\title{
Study on Plane-section Assumption of New Composite T-shaped Concrete-filled Steel Tubular Columns
}

\author{
J Huang ${ }^{1,2}$, S Q Dai ${ }^{1,}{ }^{*}$, J Y Xie ${ }^{1}$, C Wang ${ }^{1}$ \\ ${ }^{1}$ School of Civil Engineering and Architecture, Wuhan University of Technology, Wuhan 430070, \\ China \\ ${ }^{2}$ Design \& Research Institute, Wuhan University of Technology, Wuhan 430070, China \\ E-mail: 1779375740@qq.com
}

Keyword: T-shaped concrete-filled steel tubular columns; plane-section assumption; linear distribution; nonlinear finite element analysis

Abstract. The linear regularity of the strain distribution about new composite T-shaped concrete-filled steel tubular columns on the multiple sections was analyzed by ABAQUS. The plane-section assumption of new composite T-shaped concrete-filled steel tubular columns was studied under the axial loading and lateral loading, and the impact of the load angle has been analyzed. The analysis results show that the sharp change will appear on section of T-shaped concrete-filled steel tubular columns under axial loading and lateral loading, but it basically satisfies the plane-section assumption; T-shaped concrete-filled steel tubular columns basically conform to the plane-section assumption under different load angles (except the $90^{\circ}$ load angle), the influence of load angle on the plane-section assumption is not obvious.

\section{Introduction}

This research presents a new type of composite T-shaped steel pipe concrete column, which based on analyzing the study of special-shaped concrete-filled steel tubular columns at home and abroad. As shown in Figure 1, this composite column is a rectangular steel pipe directly welding with a U-shaped steel plate, and usually can be divided into T-shaped, L-shaped and Ten-shaped. On the basis of the research on the axial compression performance and seismic performance [1-9], the plane-section assumption of T steel tube concrete column is studied by ABAQUS in this paper. And the study result will lay the foundation for calculation it bending bearing capacity and nonlinear analysis.

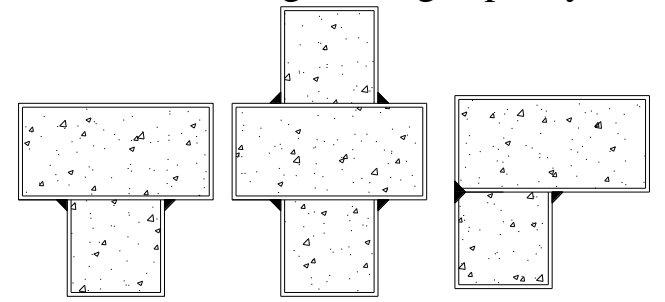

Figure1. Schematic diagram of special-shaped concrete-filled steel tubular columns

\section{Specimen Parameters}

For frame columns with fixed ends and lateral displacement at one end, assuming that it's reasonable for beam column inflection point located at the mid span, so a simplified cantilever column model is selected, and the specimen model and section size as shown in figure 2 and figure 3 . This paper selects C30 concrete, Q235 steel, and the steel tube wall thickness is $6 \mathrm{~mm}$, the column length is $3 \mathrm{~m}$.

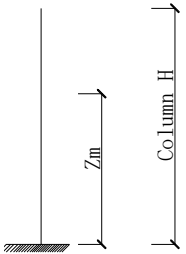

Figure2. The cantilever column model

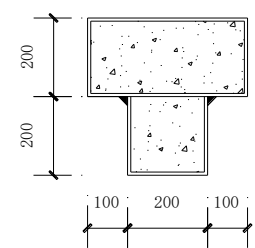

Figure3. Sectional dimensions of test pieces 


\section{Finite element model}

Constitutive relation of concrete. As shown in figure 4, the model considering the influence of the constraint effect coefficient, and the peak strain and the descending section of the stress-strain relationship of the uniaxial concrete are corrected.

Constitutive relation of steel. Idealization elastic-plastic model is adopted, as shown in Figure 5. Under the multi-axial stress states, the Von Mises yield criterion proposed by Von Mises is used for the yield criterion of steel.

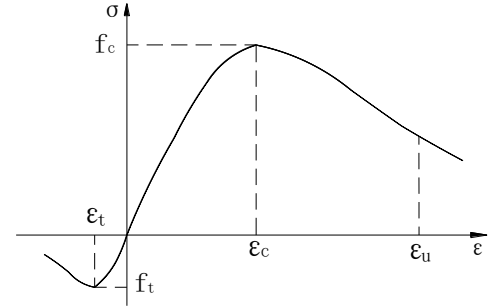

Figure4. Constitutive relation of concrete

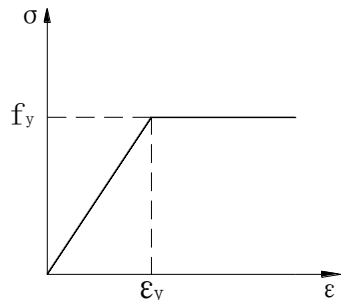

Figure5. The constitutive relation of steel

Interface model of steel and concrete. The normal contact between steel pipe and concrete adopts the penalty function ('hard contact'), and the tangential contact adopts the coulomb friction model.

Element type selection and meshing. The four-node shell element (S4R) and the eight-node three-dimensional solid element (C3D8R) are respectively selected as the steel and concrete element types. The mesh size of the steel tube and the concrete are all defined as $0.05 \mathrm{~m}$. The concrete is divided by the structured grid division technique. The steel tube is meshed by the sweeping mesh technology, as shown in Figure 6.

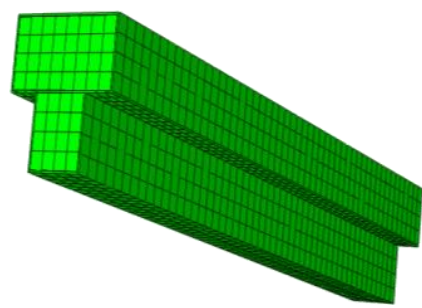

Figure6. Finite element model of T-shaped concrete-filled steel tubular columns

Constraint conditions and loading. The $\mathrm{X}, \mathrm{Y}, \mathrm{Z}$ three directions of displacement and rotation in column bottom should be constrained. The axial load on the column end is applied to the upper end of the column in the form of a uniform load, and the axial force is transmitted to the column. The top of the column is within $200 \mathrm{~mm}$ of the column as the loading zone and the horizontal load is loaded as a force on the side. The vertical load is also loaded on the top surface as surface force.

\section{Plane-section assumption under axial loading}

Set the axial compression ratio of the column to 0.4 , and applied axial loading. For a more accurate analysis of plane-section assumption for T-shaped concrete-filled steel tubular columns, the strain distributions on several sections were studied. The strain distribution of the central axis at the $\mathrm{Zm}$ section is the strain distribution at the $\mathrm{X}$-direction central axis from the bottom $\mathrm{Zm}$ section, as shown in Figure 2.

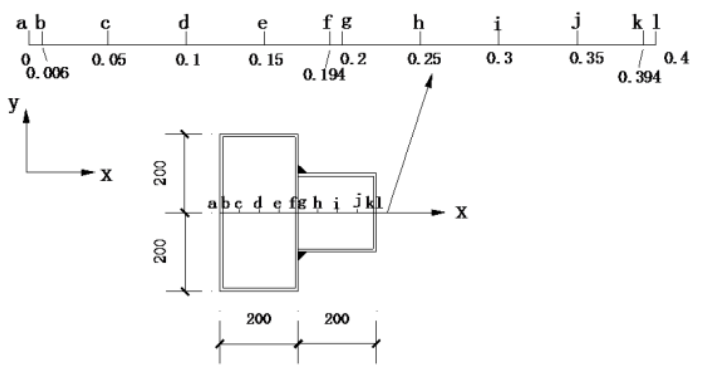

Figure7. Diagram of measuring point position 
As shown in Figure 7: a, b, c, $d$... 1 is twelve measuring points on the $X$ central axis, 0.4 represents that the most edge distance from the cross-section $X$ direction is $0 \mathrm{~m}, 0.006 \mathrm{~m} \ldots 0.394 \mathrm{~m}, 0.4 \mathrm{~m}$. The axial strain of twelve points under different stress states was analyzed by ABAQUS. In this paper, the strain is taken as the vertical axis, and the distance from the measuring point to the edge of the cross section $\mathrm{X}$ direction is taken as the horizontal axis, the distribution of strain scattergrams at different cross sections is plotted, as shown in Figure 8 to Figure 13.

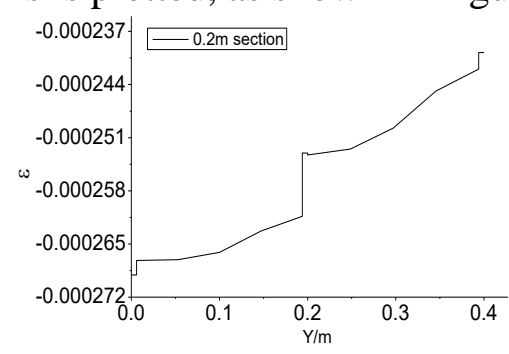

Figure8. The central axis strain distribution of $\mathrm{X}$ direction in $0.2 \mathrm{~m}$ section

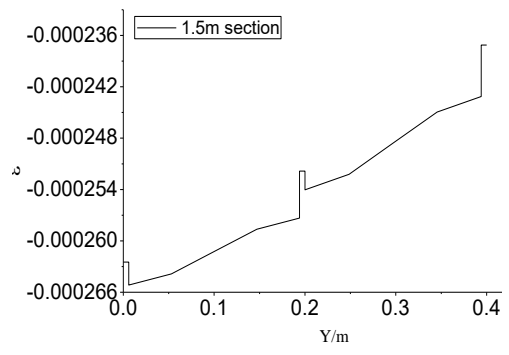

Figure10. The central axis strain distribution of $\mathrm{X}$ direction in $1.5 \mathrm{~m}$ section

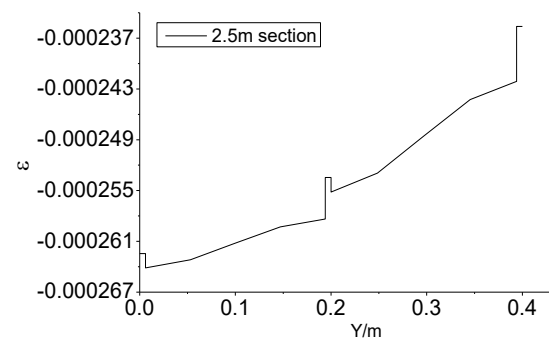

Figure12. The central axis strain distribution of $\mathrm{X}$ direction in $2.5 \mathrm{~m}$ section

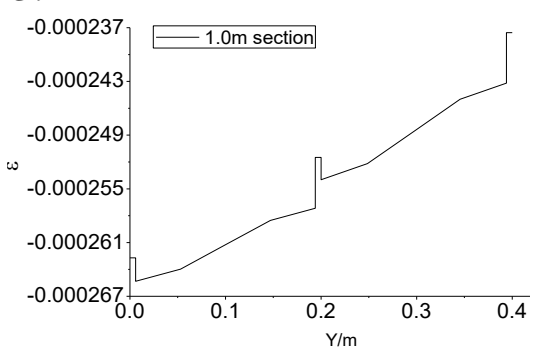

Figure9. The central axis strain distribution of $\mathrm{X}$ direction in $1.0 \mathrm{~m}$ section

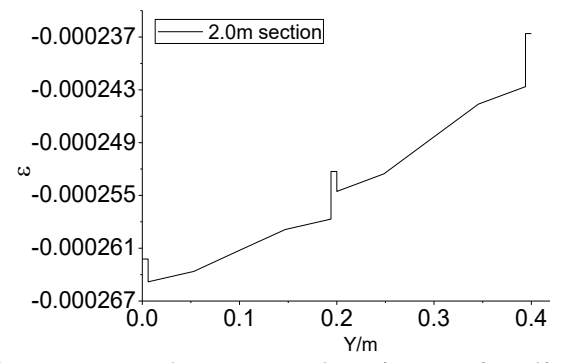

Figure11. The central axis strain distribution of $\mathrm{X}$ direction in $2.0 \mathrm{~m}$ section

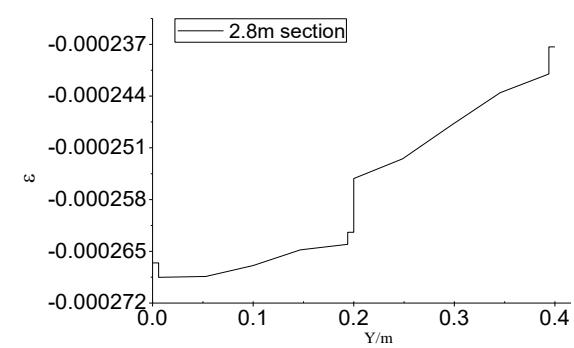

Figure13. The central axis strain distribution of $\mathrm{X}$ direction in $2.8 \mathrm{~m}$ section

As can be seen from the above strain profile, the strain distribution of T-shaped concrete-filled steel tubular columns will produce abrupt change. The site of the mutation occurs where the pipe contacts with the concrete (the middle and both ends of the cross section in the X direction), and this mutation is sometimes very large and has an adverse effect on the assumption of plane section. The reason why the mutation is mainly due to that the elastic modulus of steel is one magnitude order higher compared with that of concrete, and the deformation of steel and concrete under load is inconsistent. But the strain distribution is approximated as a straight line at some sections. The strain scatters on different cross sections have been fitted by Origin, and obtains the coefficient of determination (' $|R|$ '), as shown in Table 1.

Table 1. Fitting decomposition coefficient of strain in different sections under axial loading

\begin{tabular}{|c|c|c|c|c|c|c|c|c|}
\hline Section & $\begin{array}{c}0.1 \mathrm{~m} \\
\text { section }\end{array}$ & $\begin{array}{c}0.2 \mathrm{~m} \\
\text { section }\end{array}$ & $\begin{array}{c}0.5 \mathrm{~m} \\
\text { section }\end{array}$ & $\begin{array}{c}1.0 \mathrm{~m} \\
\text { section }\end{array}$ & $\begin{array}{c}1.5 \mathrm{~m} \\
\text { section }\end{array}$ & $\begin{array}{c}2.0 \mathrm{~m} \\
\text { section }\end{array}$ & $\begin{array}{c}2.7 \mathrm{~m} \\
\text { section }\end{array}$ & $\begin{array}{c}2.8 \mathrm{~m} \\
\text { section }\end{array}$ \\
\hline$|\mathrm{R}|$ & - & 0.94349 & 0.94743 & 0.93072 & 0.92495 & 0.91618 & 0.90178 & - \\
\hline
\end{tabular}

In the analysis of the data in the table, it can be known that under the action of the axial load, the fitting coefficient of the strain scatter fitting in the section is basically over 0.90 from $0.2 \mathrm{~m} \sim 2.7 \mathrm{~m}$, which shows that it satisfies the linear distribution. Therefore, the T-shaped concrete-filled steel 
tubular columns accord with the assumption of plane section under axial load, and the strain of section at $\mathrm{H} / 15-\mathrm{H} / 11.1$ is tribute linearly.

\section{Plane-section assumption under lateral load}

Set the axial compression ratio of the column to 0.4 , and applied axial loading, then applied to the lateral load, loaded to the steel yield (yield strength 235Mpa), this load mode makes the component in bending and torsion state. It is calculated that when the axial compression ratio is 0.3 , the lateral load is added to the yield of $92 \mathrm{kN}$, steel began to yield. When the lateral load is applied, it is divided into four load steps. The first load step applies the axial load, the second load step applies $35 \mathrm{kN}$ lateral load as the first lateral load, and the third load step applies $70 \mathrm{kN}$ lateral load as the secondary lateral load and applies $90 \mathrm{kN}$ lateral load is applied as the third lateral load in the fourth load step. The results of strain distribution are shown in Figure14 to Figure 19.

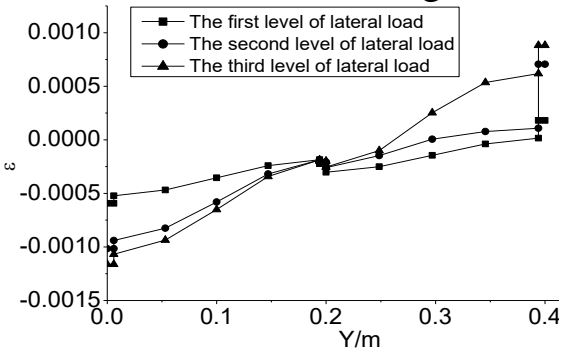

Figure14. The central axis strain distribution of $\mathrm{X}$ direction in $0.2 \mathrm{~m}$ section

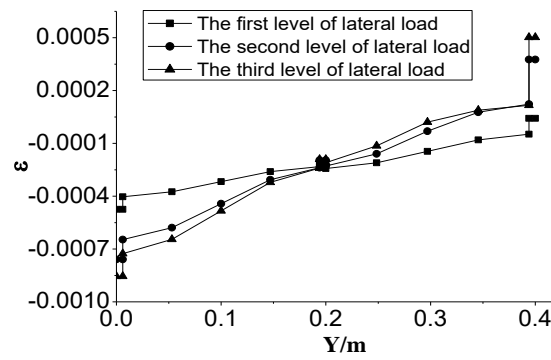

Figure16. The central axis strain distribution of $\mathrm{X}$ direction in $1.0 \mathrm{~m}$ section

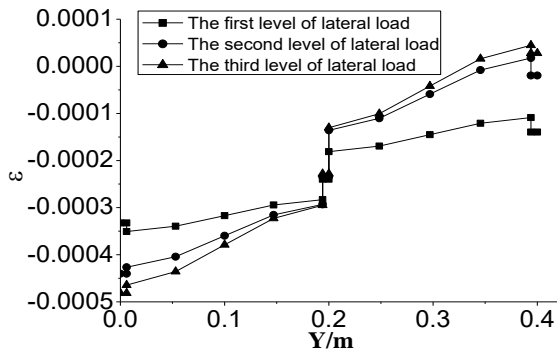

Figure18. The central axis strain distribution of $\mathrm{X}$ direction in $2.0 \mathrm{~m}$ section

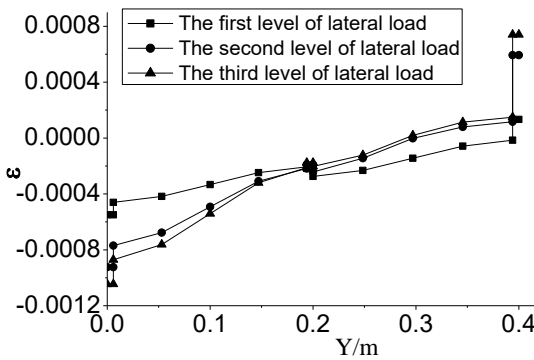

Figure15. The central axis strain distribution

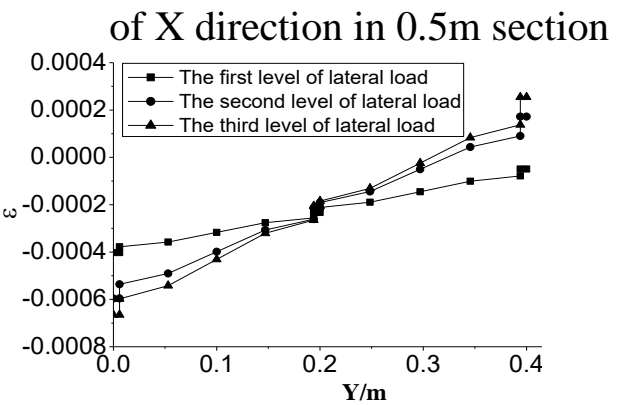

Figure17. The central axis strain distribution of $\mathrm{X}$ direction in $1.5 \mathrm{~m}$ section

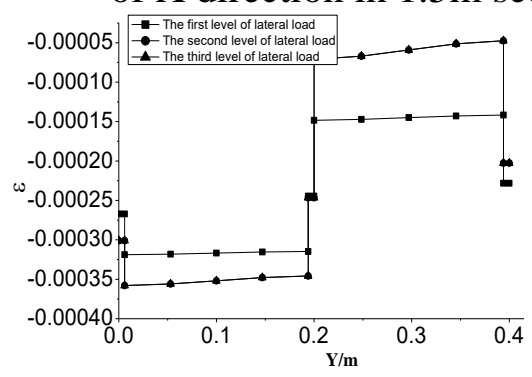

Figure19. The central axis strain distribution of $\mathrm{X}$ direction in $2.5 \mathrm{~m}$ section

As can be seen from the above strain profile, the strain distribution of T-shaped concrete-filled steel tubular columns will still have the mutation occurs where the pipe contacts with the concrete, and the size of this mutation varies with the location of the cross-section changes., in which the mutations above sections $2.2 \mathrm{~m}$ were significantly larger. The strain distribution is approximated as a straight line at sections $1.0 \mathrm{~m}$ to sections $1.8 \mathrm{~m}$. But at sections $2.2 \mathrm{~m}$ to sections $2.5 \mathrm{~m}$, the strain deviation from the straight line in the section is more serious, obviously not consistent with the linear distribution. And the determination coefficients of strain scatter fitting at different cross sections have been analyzed, as shown in Table 2 . 
Table2. Fitting decomposition coefficient of strain in different sections

\begin{tabular}{|c|c|c|c|c|c|c|c|c|}
\hline $\begin{array}{c}\text { Different } \\
\text { levels of } \\
\text { lateral load }\end{array}$ & $\begin{array}{c}0.1 \mathrm{~m} \\
\text { section }\end{array}$ & $\begin{array}{c}0.2 \mathrm{~m} \\
\text { section }\end{array}$ & $\begin{array}{c}0.5 \mathrm{~m} \\
\text { section }\end{array}$ & $\begin{array}{c}1.0 \mathrm{~m} \\
\text { section }\end{array}$ & $\begin{array}{c}1.5 \mathrm{~m} \\
\text { section }\end{array}$ & $\begin{array}{c}2.0 \mathrm{~m} \\
\text { section }\end{array}$ & $\begin{array}{c}2.1 \mathrm{~m} \\
\text { section }\end{array}$ & $\begin{array}{c}2.2 \mathrm{~m} \\
\text { section }\end{array}$ \\
\hline First level & 0.90504 & 0.92836 & 0.93333 & 0.96320 & 0.99203 & 0.90235 & - & - \\
\hline Second level & - & 0.91733 & 0.92601 & 0.96297 & 0.99091 & 0.94425 & 0.90130 & - \\
\hline Third level & - & 0.98642 & 0.91819 & 0.94713 & 0.98863 & 0.96065 & 0.92754 & - \\
\hline
\end{tabular}

By analyzing the Table2, we can know that the T-shaped concrete-filled steel tubular column under the lateral load in accordance with the assumption of plane cross-section. Under the condition of first lateral loads, the strain is linearly distributed in the range of $0.1 \mathrm{~m} \sim 2.0 \mathrm{~m}(1 / 30 \sim 1 / 1.5) \mathrm{H}$, and in the condition of second lateral loads, the strain is linearly distributed in the range of $0.2 \mathrm{~m} 2.1 \mathrm{~m}$ $(1 / 15 \sim 1 / 1.43) \mathrm{H}$. The strain is linearly distributed in the range of $0.2 \mathrm{~m} \sim 2.1 \mathrm{~m}(1 / 15 \sim 1 / 1.43) \mathrm{H}$ under the condition of third lateral loads. Therefore, the variation of the lateral load has little effect on the assumption of the column plane cross-section, and under different lateral loadings, the cross-section of the strain is linearly distributed in the range of $0.2 \mathrm{~m} \sim 2.1 \mathrm{~m}(1 / 15 \sim 1 / 1.43) \mathrm{H}$.

\section{The effect of loading angle}

The cross-section of the T-shaped columns of concrete-filled steel tubes is symmetrical about the $\mathrm{i}-\mathrm{i}$ axis, and the loading angle is studied only when the loading angle is $0^{\circ}, 45^{\circ}, 90^{\circ}, 135^{\circ}$, and $180^{\circ}$. To ensure that the force $F$ does not change, by changing the size of $F_{x} 、 F_{y}$ to change the loading angle. The strain distribution under the loading angle is shown in Figure20 to Figure25. It can be seen from the above analysis that the strain on the cross section will produce a sudden change in the contact area between the steel tube and the concrete under different loading angles. And in order to further study the influence of loading angle, the fitting coefficient of different strain points have been analyzed, as shown in table 3.

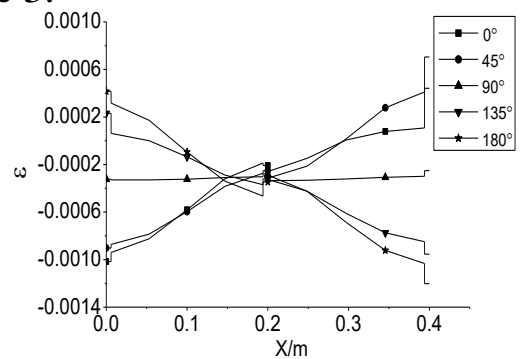

Figure20. Strain distribution in $0.2 \mathrm{~m}$ section

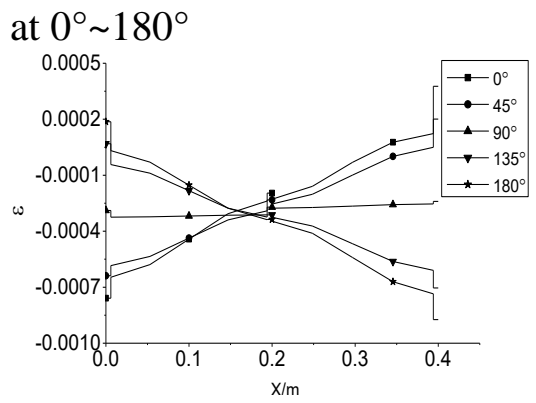

Figure22. Strain distribution in $1.0 \mathrm{~m}$ section at $0^{\circ} \sim 180^{\circ}$

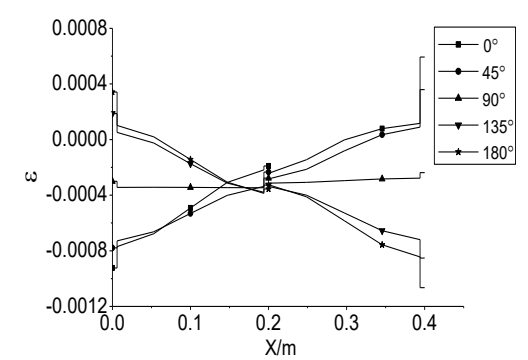

Figure21. Strain distribution in $0.5 \mathrm{~m}$ section

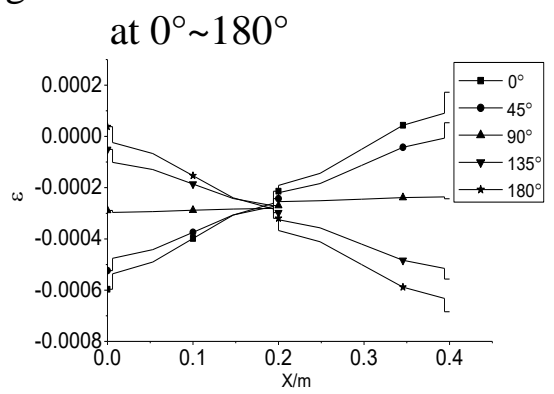

Figure23. Strain distribution in $1.5 \mathrm{~m}$ section at $0^{\circ} \sim 180^{\circ}$ 


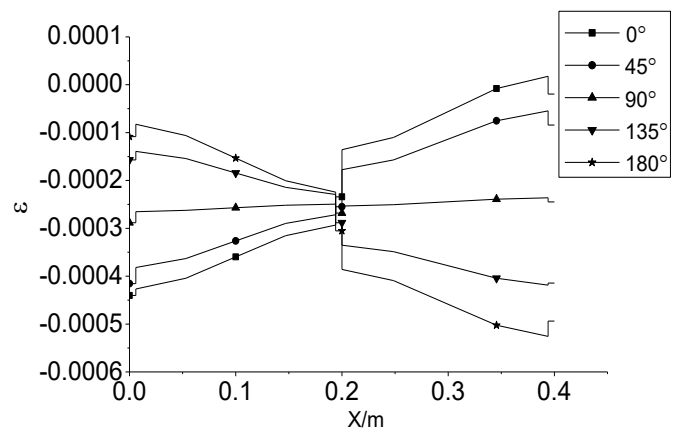

Figure24. Strain distribution in $2.0 \mathrm{~m}$ section at $0^{\circ} \sim 180^{\circ}$

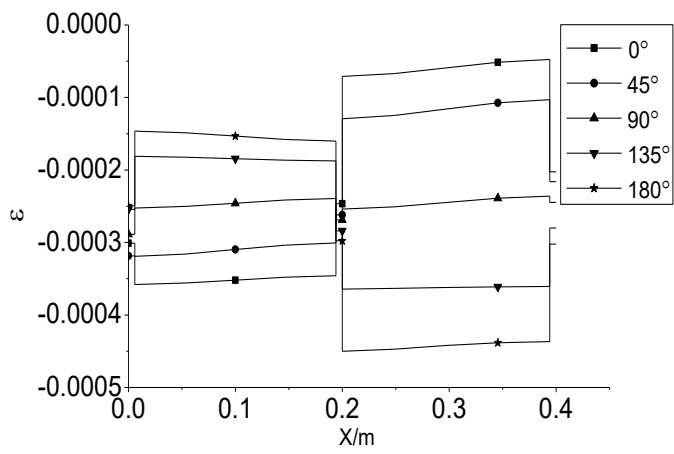

Figure25. Strain distribution in $2.5 \mathrm{~m}$ section at $0^{\circ} \sim 180^{\circ}$

Table3. The fitting coefficient of different strain points under different loading angles

\begin{tabular}{|c|c|c|c|c|c|}
\hline Section & $0^{\circ}$ & $45^{\circ}$ & $90^{\circ}$ & $135^{\circ}$ & $180^{\circ}$ \\
\hline $0.1 \mathrm{~m}$ & - & 0.93377 & - & 0.97104 & 0.92911 \\
\hline $0.2 \mathrm{~m}$ & 0.91733 & 0.98987 & - & 0.97961 & 0.97437 \\
\hline $0.5 \mathrm{~m}$ & 0.92601 & 0.96237 & - & 0.97030 & 0.95660 \\
\hline $1.0 \mathrm{~m}$ & 0.96297 & 0.97716 & - & 0.97709 & 0.97602 \\
\hline $1.5 \mathrm{~m}$ & 0.99091 & 0.99096 & - & 0.99094 & 0.99232 \\
\hline $1.9 \mathrm{~m}$ & 0.97007 & 0.97532 & - & 0.96501 & 0.96066 \\
\hline $2.0 \mathrm{~m}$ & 0.94425 & 0.95605 & - & 0.93729 & 0.93265 \\
\hline $2.1 \mathrm{~m}$ & - & 0.92334 & - & - & - \\
\hline $2.2 \mathrm{~m}$ & - & - & - & - & - \\
\hline
\end{tabular}

Analysis of Table 3 shows that the section strain scatter fitting coefficients between $0.2 \mathrm{~m}$ to $2.0 \mathrm{~m}$ section are more than 0.90 under different loading angles (except $90^{\circ}$ loading angle), indicating that the strain distribution in line with the linear distribution, and the action of T-shaped concrete-filled steel tubular column in line with the plane-section assumption (except $90^{\circ}$ loading angle). The section strain does not accord with the linear distribution under $90^{\circ}$ loading angle, so it does not conform to the plane-section assumption. The reason for this situation is because at $90^{\circ}$ loading angle, the lateral load is applied only $F_{y}$ without the application of $F_{x}$, the bending is mainly bending along the neutral axis of bending, and other angles are generated under the action of bending around the neutral axis. However, in the actual project will not have a purely 90 degree loading angle, so the assumption of the plane section is still established.

\section{Conclusion}

In this paper, the plane section assumption of new composite T-shaped concrete-filled steel tubular columns under axial load and lateral load is studied, and by analysis the effect of loading angle, the follow conclusions can be drawn:

(1) Under the action of axial load, the T-shaped concrete-filled steel tubular columns are in accordance with the assumption of plane section. The strain distribution of the T-shaped concrete-filled steel tube is linearly distributed in the range of $(1 / 15$ to $1 / 11.1) \mathrm{H}$.

(2) When the axial compression ratio is 0.3 , the T-shaped concrete-filled steel tubular column under the lateral load is consistent with the assumption of plane cross-section, the strain distribution in the cross section is linearly distributed in the range of $0.2 \mathrm{~m} \sim 2.0 \mathrm{~m}(1 / 15 \sim 1 / 1.5)$.

(3) When the axial compression ratio is 0.3 , the T-shape concrete-filled steel tubular columns can meet the assumption of plane cross-section at different loading angles. The strain distribution conforms to the linear distribution range of $0.2 \mathrm{~m} \sim 2.0 \mathrm{~m}(1 / 15 \mathrm{H} \sim 1 / 1.5 \mathrm{H})$; the loading angle has little influence on the T-shaped concrete-filled steel tube. 


\section{Acknowledgements}

This work was financially supported by the Yellow crane talent (City construction) project (20161j0013).

\section{References}

[1] Lin Mingsen, Dai Shaobin, Liu Jixiong \& Peng Zhong, 2012. Experimental study on seismic performance of end-plate connections of concrete-filled steel tube T-section column and steel beam [J]. Earthquake Engineering and Engineering Vibration, 2012, 32(2): 114-119.

[2] Cao Bing, Dai Shaobin, Lin Mingsen, etc., 2012. Experimental study on seismic performance of connections between T-shaped concrete-filled steel column and steel beam [J]. Applied Mechanics and Materials, 2012, 204-208: 2455-2460.

[3] Cao Bing, Dai Shaobin, Huang Jun, etc., 2012. Research on load-displacement skeleton curve model of L-shaped concrete-filled steel tubular column [J]. Advances in Civil Engineering and Building Materials, 2012, 514-518: 655-659.

[4] Cao Bing, Dai Shaobin, Huang Jun, 2013. Orthogonal analysis on T-shaped concrete-filled steel tubular column seismic performance based on finite element calculation results [J]. Advanced Materials Research.Vols.671-674, pp 523-528,2013.

[5] Cao Bing, Dai Shaobin, Huang Jun, 2013. Research on load-displacement skeleton curve model of T-shaped concrete-filled steel tubular column [J]. Journal of Hefei University of Technology, 2013, 36 (10):1222-1226, 1258.

[6] Liu JiXiong, Dai Shaobin, Peng Yao, etc., 2013. Experimental and numerical studies on the joint of special-shaped concrete-filled rectangular composite tubular column with H-shaped beam. Advanced Materials Research, 2013, 671-674: 417-423.

[7] Cao Bing, 2013. Nonlinear finite element analysis on seismic performance of T-shaped steel tubular column. Wu Han: Wuhan University of Technology master degree thesis, 2013.

[8]Lin Hong, Liu JiXiong, Liu Ming, etc., 2014. Comparison analysis of evaluation criterions for vibration serviceability induced by wind load [J]. Applied Mechanical and Materials, 2014, 578-579: 653-658.

[9] Liu Jixiong, Dai Shaobin, Huo Kaicheng, etc., 2015. Study on earthquake behavior of top and seat angle joint of special-shaped concrete-filled rectangular composite tubular column with steel beam [J]. Journal of Sichuan university (engineering science edition), 2015, 47 (1) : 128-137. 